\title{
An analytical solution for stresses and deformations of tunnels in a non-uniform stress field based on strain-softening model and Mogi-Coulomb criterion
}

\author{
Hao Fan ${ }^{a}$ (D), Lianguo Wang** (D), Wanrong Liub \\ a State Key Laboratory for Geomechanics and Deep Underground Engineering, China University of Mining and Technology, Xuzhou 221116, \\ China. E-mail: fanhao2014@126.com, cumt_lgwang@163.com \\ b School of Physical Science and Information Technology, Liaocheng University, Liaocheng 252059, China. E-mail: \\ wanrongliu1989@163.com \\ ${ }^{*}$ Corresponding author
}

http://dx.doi.org/10.1590/1679-78255801

\begin{abstract}
In this study, a mechanical model for tunnels excavated in a non-uniform stress field is developed. A new strain-softening model simultaneously considers the weakening of cohesion and internal friction angle is proposed. Then, an analytical solution for the post-peak region radii, stresses, and displacements is deduced. Taking a tunnel in Taoyuan coal mine as an engineering example, the post-peak region radii, surface displacement, and stresses distribution are determined. The effects of the horizontal-to-vertical stress ratio, intermediate principal stress, residual cohesion, and residual internal friction angle on tunnel deformations are discussed. The results show that the post-peak region radii and stresses distribution around the tunnel varies with direction due to the non-uniform stress field. The post-peak region radii and surface displacement are larger with consideration of intermediate principal stress. Tunnels surrounded by rock masses with a higher residual cohesion and internal friction angle experience lower post-peak region radii and surface displacement.
\end{abstract}

\section{Keywords}

Tunnels; non-uniform stress field; analytical solution; intermediate principal stress; strain-softening model

\section{Graphical Abstract}

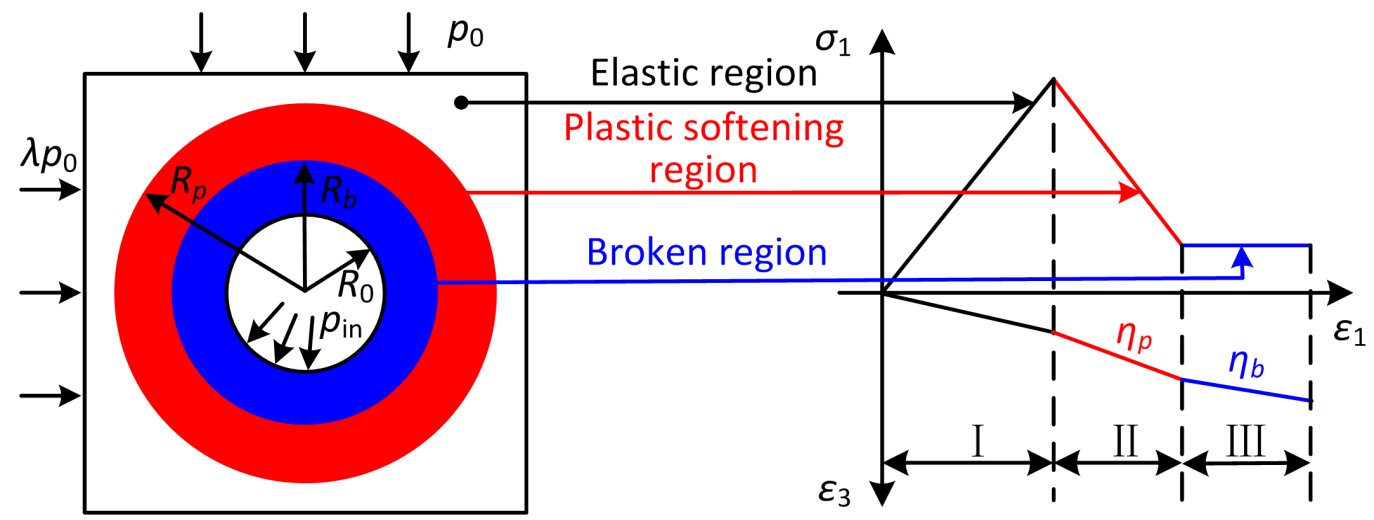




\section{INTRODUCTION}

Tunnels are common structures in civil engineering, underground traffic engineering, and mining engineering. After tunnel excavation, the original stress state is disrupted, which causes deformation, displacement, and even destruction of rock masses around the tunnel (Brown et al. 1983). Accurate calculations for stresses and deformations of the surrounding rock play an important role in evaluating tunnel stability and designing the support system (Cui et al. 2015, Mohammad and Ahmad 2016). In early work, Park (2015), Park and Kim (2006), Sharan (2003, 2008), and Wang et al. (2019) analyzed the stresses and strains of the surrounding rock by regarding the stress condition of tunnels as a uniform stress field for simplicity. However, considerable field measurements have indicated that the insitu stress in the horizontal and vertical directions vary due to the faults, folds and other geological structures in underground coal mines (Wang et al. 2000, Zhao et al. 2013). Tunnels are thus subjected to a non-uniform stress field with a horizontal-to-vertical stress ratio not equal to one, which has a significant impact on the stresses distribution and displacement of the surrounding rock (Shen 2013). Therefore, it is expected that the theoretical analysis of tunnels should take the horizontal-to-vertical stress ratio into consideration (Detournay and Fairhurst 1987, Detournay and St. John 1988, Galin 1946, Simanjuntak et al. 2014).

Strength criteria are another crucial component of tunnels analysis. In past decades, research was carried out by using the linear Mohr-Coulomb strength criterion (Alejano et al. 2009, Mohammad and Ahmad 2015), nonlinear HoekBrown strength criterion (Alejano et al. 2010, Sharan 2003), and generalized Hoek-Brown strength criterion (Chen and Tonon 2011, Sharan 2008); however, the influence of the intermediate principal stress on the rock mass strength was ignored, which had an unfavorable effect on the tunnel support design. In practice, the rock mass is in a true triaxial stress state, and numerous experiments have confirmed that the intermediate principal stress has a significant effect on rock strength (Jiang et al. 2019, Li et al. 2019, Mogi 1981). Thus, the intermediate principal stress is essential to engineering applications. The Mogi-Coulomb strength criterion reasonably considers the influence of intermediate principal stress and better reflects the properties of rock under true triaxial stress (Al-Ajmi and Zimmerman 2005, Benz and Schwab 2008, Zhang et al. 2010, Singh et al. 2017, 2018). Therefore, the Mogi-Coulomb criterion is selected as the strength criterion for the rock mass in this study.

It is known that most of the rock mass undergoes strength attenuation after peaking (Lu et al. 2010, Wang et al. 2010a), which is called "strain-softening." Previous analytical solutions for tunnels in strain-softening materials have primarily considered a decrease in cohesion, whereas variations in internal friction angle have been neglected (Han et al. 2013, Wang et al. 2010b, Zhang et al. 2012). The internal friction angle also shows a decreasing trend in the post-peak stage (Li et al. 2015).

In the present study, a mechanical model for a circular tunnel subjected to a non-uniform stress field is established. A strain-softening model that simultaneously considers the weakening of cohesion and internal friction angle is proposed. Based on the strain-softening model and Mogi-Coulomb criterion, a unified solution for the stresses and displacement of the surrounding rock is determined. Taking a tunnel in the Taoyuan coal mine as an engineering example, the post-peak region radii, surface displacement, and stresses distribution are determined by the newly developed theoretical solution. Finally, the sensitivity of the geomechanical parameters on the tunnel deformations is analyzed.

\section{DEFINITION OF THE PROBLEM}

\subsection{Mechanical model of a circular tunnel in a non-uniform stress field}

A circular tunnel of radius $R_{0}$ was excavated in an infinite rock mass (Figure 1 ). The vertical and horizontal stresses are $p_{0}$ and $\lambda p_{0}$, respectively, where $\lambda$ is the horizontal-to-vertical stress ratio. A support pressure $\left(p_{s}\right)$ is uniformly distributed along the excavation surface. The surrounding rock of the tunnel is subdivided into elastic region (" $e$ "), plastic softening region (" $p$ "), and broken region (" $b$ "). The radii of the plastic softening and broken regions are denoted by $R_{p}$ and $R_{b}$, respectively. 


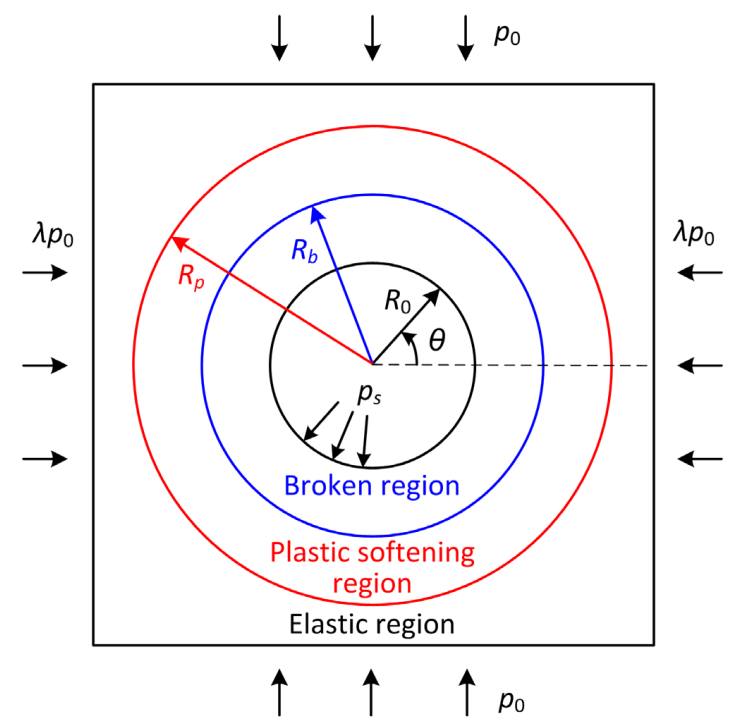

Figure 1: Mechanical model for a tunnel in a non-uniform stress field after excavation.

\subsection{Strain-softening model}

Once the stress exceeds the peak strength, the rock enters a post-peak softening stage. Both the cohesion $(c)$ and internal friction angle $(\varphi)$ of the rock mass gradually decrease to the residual value in this stage. Assuming that the cohesion and internal friction angle linearly decrease with the shear strain $\left(\varepsilon_{\vartheta p}\right)$ in the strain-softening stage (Figure 2 ), the cohesion $\left(c_{p}\right)$ and internal friction angle $\left(\varphi_{p}\right)$ in the plastic softening region can be expressed as:

$\left\{\begin{array}{l}c_{p}=S_{c}\left(\varepsilon_{\theta p}-\varepsilon_{\theta}^{R_{p}}\right)+c_{0} \\ \varphi_{p}=S_{\varphi}\left(\varepsilon_{\theta p}-\varepsilon_{\theta}^{R_{p}}\right)+\varphi_{0}\end{array}\right.$

where $S_{c}$ and $S_{\varphi}$ are the softening coefficients of the cohesion and internal friction angle in the plastic softening region, respectively; $c_{0}$ and $\varphi_{0}$ are the initial cohesion and initial friction angle, respectively; and $\varepsilon_{\theta} R_{p}$ is the shear strain at the interface between the elastic and plastic softening regions.

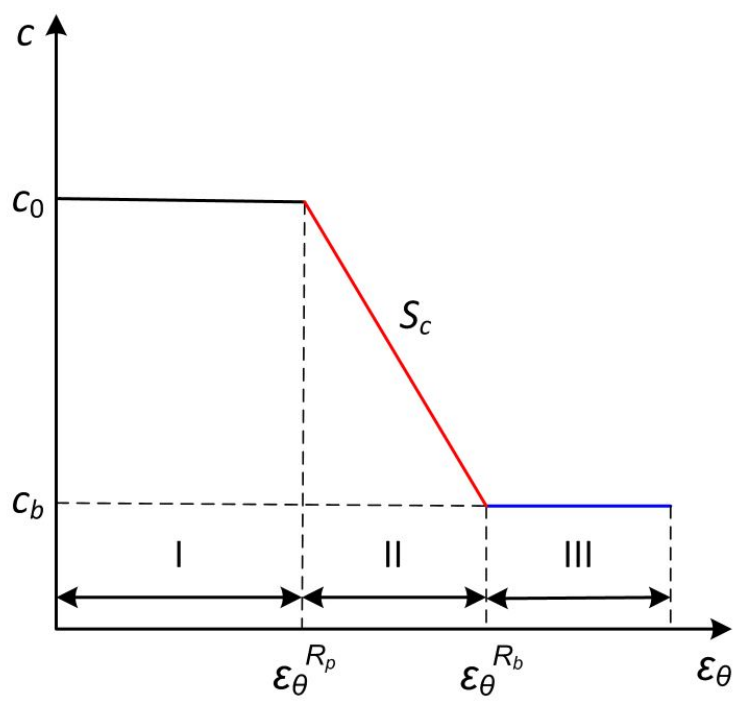

(a) Softening model of the cohesion

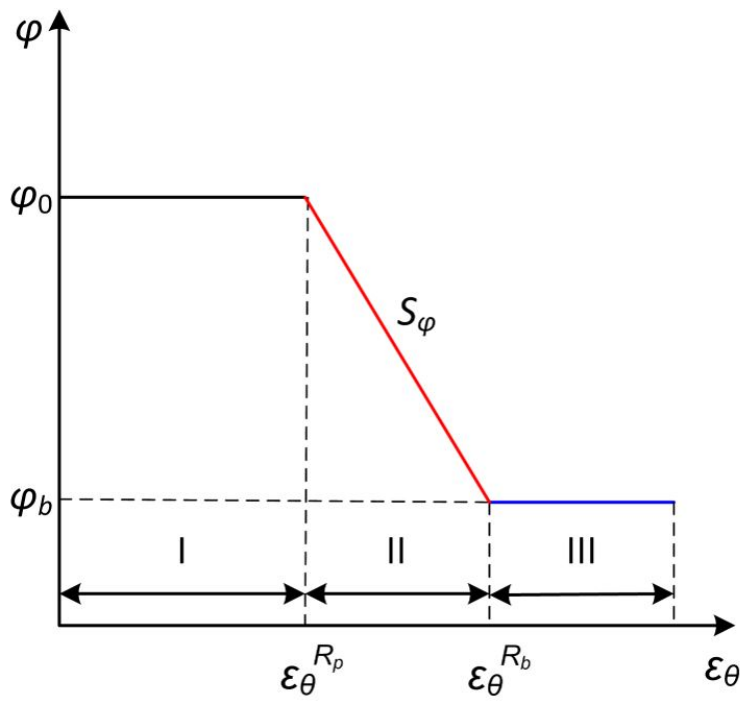

(b) Softening model of the internal friction angle

Figure 2: Softening model of the cohesion and internal friction angle (I: Elastic stage; II: Strain-softening stage; III: Damage stage). 


\subsection{Mogi-Coulomb strength criterion}

Mogi (1971) and Chang and Haimson (2012) considered that the Mogi-Coulomb criterion can be expressed as a function between the octahedral shear stress $\left(\tau_{\mathrm{oct}}\right)$ and the average effective normal stress $\left(\sigma_{\mathrm{m}, 2}\right)$ :

$$
\begin{aligned}
& \tau_{\text {oct }}=\frac{2 \sqrt{2}}{3} c \cos \varphi+\frac{2 \sqrt{2}}{3} \sin \varphi \cdot \sigma_{\mathrm{m}, 2} \\
& \tau_{\text {oct }}=\frac{1}{3} \sqrt{\left(\sigma_{1}-\sigma_{2}\right)^{2}+\left(\sigma_{2}-\sigma_{3}\right)^{2}+\left(\sigma_{3}-\sigma_{1}\right)^{2}} \\
& \sigma_{\mathrm{m}, 2}=\frac{\sigma_{1}+\sigma_{3}}{2}
\end{aligned}
$$

where $\sigma_{1}, \sigma_{2}$, and $\sigma_{3}$ are the maximum, intermediate, and minimum principal stresses, respectively. For axisymmetric plane strain problems, the radial stress $\left(\sigma_{r}\right)$, axial stress $\left(\sigma_{z}\right)$, and tangential stress $\left(\sigma_{\vartheta}\right)$ in the surrounding rock of a tunnel can be regarded as $\sigma_{1}, \sigma_{2}$, and $\sigma_{3}$, respectively. The relationship among the three principal stresses can be expressed as:

$\sigma_{z}=\sigma_{2}=\frac{\sigma_{1}+\sigma_{3}}{2}=\frac{\sigma_{r}+\sigma_{\theta}}{2}$

According to Eqs. (2)-(5), the Mogi-Coulomb criterion can be rewritten as:

$\sigma_{\theta i}=M_{i} \sigma_{r i}+N_{i}$

where $M_{i}=\left(\sqrt{3}+2 \sin \varphi_{i}\right) /\left(\sqrt{3}-2 \sin \varphi_{i}\right), N_{i}=4 c_{i} \cos \varphi_{i} /\left(\sqrt{3}-2 \sin \varphi_{i}\right)$, and $\varphi_{i}$ and $c_{i}$ are the cohesion and internal friction angle in different regions, respectively. The subscript symbol "i" can be replaced by " $e$," " $p$," and " $b$."

\section{UNIFIED SOLUTION OF THE CIRCULAR TUNNELS IN A NON-UNIFORM STRESS FIELD}

\subsection{Basic equations}

The equilibrium differential equation for the different regions of surrounding rock can be written as:

$\frac{d \sigma_{r i}}{d r}+\frac{\sigma_{r i}-\sigma_{\theta i}}{r}=0$

where $\sigma_{r i}$ and $\sigma_{\vartheta i}$ are the radial and tangential stresses in different regions, respectively.

The geometric equation can be expressed as:

$\left\{\begin{array}{l}\varepsilon_{r i}=\frac{d u_{i}}{d r} \\ \varepsilon_{\theta i}=\frac{u_{i}}{r}\end{array}\right.$

where $\varepsilon_{r i}$ and $\varepsilon_{\vartheta i}$ are the radial and tangential strains in different regions, respectively, and $u_{i}$ represents the displacement in different regions.

In addition, the strains in different regions should satisfy the constitutive equations: 


$$
\left\{\begin{array}{l}
\varepsilon_{r i}=\frac{1-\mu^{2}}{E}\left(\sigma_{r i}-\frac{\mu}{1-\mu} \sigma_{\theta i}\right) \\
\varepsilon_{\theta i}=\frac{1-\mu^{2}}{E}\left(\sigma_{\theta i}-\frac{\mu}{1-\mu} \sigma_{r i}\right)
\end{array}\right.
$$

where $\mu$ and $E$ are the Poisson's ratio and Young's modulus of the rock mass, respectively.

Generally, rock mass volume varies in the plastic softening and broken regions, and the relationship between the radial and tangential strains can be established by adopting a non-associated linear flow rule as:

$\varepsilon_{r i}+\eta_{i} \varepsilon_{\theta i}=0$

where $\eta_{i}=\left(1+\sin \psi_{i}\right) /\left(1-\sin \psi_{i}\right)$, which is the dilation coefficient in different regions, and $\psi_{i}$ is the dilation angle.

\subsection{Stresses and displacement in the elastic region $\left(R_{p} \leq r<\infty\right)$}

The non-uniform stress field can be decomposed into two stress states, as shown in Figure 3 . In state I, the surrounding rock is subjected to a uniform pressure $\left(0.5(1+\lambda) p_{0}\right)$ and a support pressure $\left(p_{s}\right)$, and the stresses in the elastic region can be written as:

$$
\left\{\begin{array}{l}
\sigma_{r}=\frac{1}{2}(1-\lambda) p_{0}\left(1-\frac{R_{p}^{2}}{r^{2}}\right)+\sigma_{r} R_{p} \frac{R_{p}^{2}}{r^{2}} \\
\sigma_{\theta}=\frac{1}{2}(1-\lambda) p_{0}\left(1+\frac{R_{p}^{2}}{r^{2}}\right)-\sigma_{r} R_{p} \frac{R_{p}^{2}}{r^{2}}
\end{array}\right.
$$

where $\sigma_{r}{ }_{p}$ is the radial stress on the interface between the elastic and plastic softening regions.

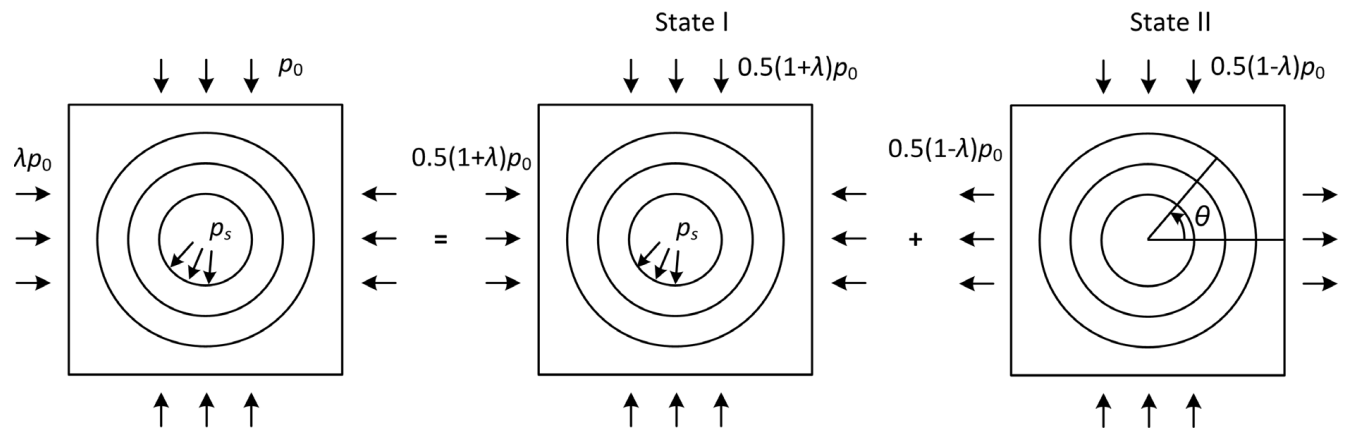

Figure 3: Decomposition model of a non-uniform stress field.

In state II, the surrounding rock is subjected to a horizontal tension $\left(0.5(1-\lambda) p_{0}\right)$ and a vertical pressure $\left(0.5(1-\lambda) p_{0}\right)$. The boundary condition at $r=R_{0}$ can be expressed as:

$\sigma_{r}=\tau_{r \theta}=0$

At $r=R_{s}, \sigma_{x}=-0.5(1-\lambda) p_{0}, \sigma_{y}=0.5(1-\lambda) p_{0}$, and $\tau_{r \vartheta}=0$. Thus, the boundary condition at $r=R_{s}$ can be obtained by the coordinate transformation:

$\left\{\begin{array}{l}\sigma_{r}=-0.5(1-\lambda) p_{0} \cos 2 \alpha \\ \tau_{r \theta}=0.5(1-\lambda) p_{0} \sin 2 \alpha\end{array}\right.$

where $\alpha=\frac{\pi}{2}-\theta$. An assumed stress function is given as: 
$\Phi=f(r) \cos 2 \theta$

$\nabla^{4} \Phi=0$

The biharmonic equation is expressed as:

By substituting Eq. (14) into Eq. (15), the following can be obtained:

$\frac{d^{4} f(r)}{d r^{4}}+\frac{2}{r} \frac{d^{3} f(r)}{d r^{3}}-\frac{9}{r^{2}} \frac{d^{2} f(r)}{d r^{2}}+\frac{9}{r^{3}} \frac{d f(r)}{d r}=0$

The general solution of Eq. (16) is:

$f(r)=A r^{4}+B r^{3}+C+D r^{-2}$

where $A, B, C$, and $D$ are integral constants. The stress function can be rewritten as:

$\Phi=\left(A r^{4}+B r^{3}+C+D r^{-2}\right) \cos 2 \theta$

Therefore, the stresses can be deduced as:

$$
\left\{\begin{array}{l}
\sigma_{r}=\frac{1}{r} \frac{\partial \varphi}{\partial r}+\frac{1}{r^{2}} \frac{\partial^{2} \varphi}{\partial \theta^{2}}=-\left(2 B+\frac{4 C}{r^{2}}+\frac{6 D}{r^{4}}\right) \cos 2 \theta \\
\sigma_{\theta}=\frac{\partial^{2} \varphi}{\partial r^{2}}=\left(12 A r^{2}+2 B+\frac{6 D}{r^{2}}\right) \cos 2 \theta \\
\tau_{r \theta}=-\frac{\partial \varphi}{\partial r}\left(\frac{1}{r} \frac{\partial \varphi}{\partial \theta}\right)=\left(6 A r^{2}+2 B-\frac{2 C}{r^{2}}-\frac{6 D}{r^{4}}\right) \sin 2 \theta
\end{array}\right.
$$

The integral constants can be determined by the boundary conditions Eq. (12) and Eq. (13) as:

$\left\{\begin{array}{l}A=0 \\ B=\frac{1}{4}(1-\lambda) p_{0} \\ C=\frac{1}{2}(1-\lambda) p_{0} R_{p}^{2} \\ D=\frac{1}{4}(1-\lambda) p_{0} R_{p}^{4}\end{array}\right.$

Therefore, Eq. (19) can be rewritten as:

$$
\left\{\begin{array}{l}
\sigma_{r}=-\frac{1}{2}(1-\lambda) p_{0}\left(1-4 \frac{R_{p}^{2}}{r^{2}}+3 \frac{R_{p}^{4}}{r^{4}}\right) \cos 2 \theta \\
\sigma_{\theta}=\frac{1}{2}(1-\lambda) p_{0}\left(1+3 \frac{R_{p}^{4}}{r^{4}}\right) \cos 2 \theta \\
\tau_{r \theta}=\frac{1}{2}(1-\lambda) p_{0}\left(1+2 \frac{R_{p}^{2}}{r^{2}}-3 \frac{R_{p}^{4}}{r^{4}}\right) \sin 2 \theta
\end{array}\right.
$$


In summary, the stresses in the elastic region under a non-uniform stress field can be obtained by superimposing Eq. (11) and Eq. (21):

$$
\left\{\begin{array}{l}
\sigma_{r e}=\frac{1}{2}(1+\lambda) p_{0}\left(1-\frac{R_{p}^{2}}{r^{2}}\right)+\sigma_{r} R_{s} \frac{R_{p}^{2}}{r^{2}}-\frac{1}{2}(1-\lambda) p_{0}\left(1-4 \frac{R_{p}^{2}}{r^{2}}+3 \frac{R_{p}^{4}}{r^{4}}\right) \cos 2 \theta \\
\sigma_{\theta e}=\frac{1}{2}(1+\lambda) p_{0}\left(1+\frac{R_{p}^{2}}{r^{2}}\right)-\sigma_{r} R_{s} \frac{R_{p}^{2}}{r^{2}}+\frac{1}{2}(1-\lambda) p_{0}\left(1+3 \frac{R_{p}^{4}}{r^{4}}\right) \cos 2 \theta
\end{array}\right.
$$

The radial and tangential stresses in the elastic region should satisfy Eq. (6) at $r=R_{p}$. Thus, $\sigma_{r}^{R_{p}}$ can be determined by substituting Eq. (22) into Eq. (6):

$\sigma_{r}^{R_{p}}=\frac{(1+\lambda) p_{0}+2(1-\lambda) p_{0} \cos 2 \theta-N_{e}}{M_{e}+1}$

The radial and tangential strains in the elastic region can be derived by substituting Eq. (22) into Eq. (9):

$$
\left\{\begin{array}{l}
\varepsilon_{r e}=\frac{1+\mu}{E}\left\{\frac{1}{2}(1+\lambda) p_{0}\left[(1-2 \mu)-\frac{R_{p}^{2}}{r^{2}}\right]+\sigma_{r} R_{p} \frac{R_{p}^{2}}{r^{2}}-\frac{1}{2}(1-\lambda) p_{0}\left[1-4(1-\mu) \frac{R_{p}^{2}}{r^{2}}+3 \frac{R_{p}^{4}}{r^{4}}\right] \cos 2 \theta\right\} \\
\varepsilon_{\theta e}=\frac{1+\mu}{E}\left\{\frac{1}{2}(1+\lambda) p_{0}\left[(1-2 \mu)+\frac{R_{p}^{2}}{r^{2}}\right]-\sigma_{r} R_{p} \frac{R_{p}^{2}}{r^{2}}+\frac{1}{2}(1-\lambda) p_{0}\left(1-4 \mu \frac{R_{p}^{2}}{r^{2}}+3 \frac{R_{p}^{4}}{r^{4}}\right) \cos 2 \theta\right\}
\end{array}\right.
$$

Using Eq. (8), the displacement in the elastic region can be easily obtained as:

$$
u_{e}=\frac{1+\mu}{E}\left\{\frac{1}{2}(1+\lambda) p_{0}\left[(1-2 \mu) r+\frac{R_{p}^{2}}{r}\right]-\sigma_{r} R_{p} \frac{R_{p}^{2}}{r}+\frac{1}{2}(1-\lambda) p_{0}\left(r-4 \mu \frac{R_{p}^{2}}{r}+3 \frac{R_{p}^{4}}{r^{3}}\right) \cos 2 \theta\right\}
$$

\subsection{Stresses and displacement in the plastic softening region $\left(R_{b} \leq r<R_{p}\right)$}

Combined with the boundary condition of $\sigma_{r}=\sigma_{r}{ }^{R_{p}}$ at $r=R_{p}$, the stresses in the plastic softening region can be derived by substituting Eq. (6) into Eq. (7):

$$
\left\{\begin{array}{l}
\sigma_{r p}=\frac{N_{p}}{1-M_{p}}+\left(\sigma_{r}^{R_{p}}-\frac{N_{p}}{1-M_{p}}\right)\left(\frac{R_{p}}{r}\right)^{1-M_{p}} \\
\sigma_{\theta p}=\frac{N_{p}}{1-M_{p}}+M_{p}\left(\sigma_{r}^{R_{p}}-\frac{N_{p}}{1-M_{p}}\right)\left(\frac{R_{p}}{r}\right)^{1-M_{p}}
\end{array}\right.
$$

In the plastic softening region, the total strains can be decomposed into elastic and plastic parts as follows:

$$
\left\{\begin{array}{l}
\varepsilon_{r}=\varepsilon_{r p}+\varepsilon_{r}^{R_{p}} \\
\varepsilon_{\theta}=\varepsilon_{\theta p}+\varepsilon_{\theta}^{R_{p}}
\end{array}\right.
$$

where $\varepsilon_{r}{ }^{R_{p}}$ and $\varepsilon_{\theta}{ }^{R_{p}}$ are the radial and tangential strains at the interface between the elastic and plastic softening regions, respectively.

The displacement differential equation can be given by integrating Eqs. (8), (9), and (27): 
$\frac{d u_{p}}{d r}+\eta_{p} \frac{u_{p}}{r}=\varepsilon_{r}^{R_{p}}+\eta_{p} \cdot \varepsilon_{\theta}^{R_{p}}$

The displacement in the plastic softening region can be derived by solving Eq. (28) with the boundary condition $u_{p}=u_{e}$ at $r=R_{p}$ :

$u_{p}=\left[u_{e}^{R_{p}}-\frac{\left(\varepsilon_{r}^{R_{p}}+\eta_{p} \varepsilon_{\theta}^{R_{p}}\right) R_{p}}{\eta_{p}+1}\right]\left(\frac{R_{p}}{r}\right)^{\eta_{p}}+\frac{\left(\varepsilon_{r}^{R_{p}}+\eta_{p} \varepsilon_{\theta}^{R_{p}}\right) r}{\eta_{p}+1}$

where $u_{e} R_{p}$ is the displacement at the interface between the elastic and plastic softening regions.

The strains in the plastic softening region can be determined by substituting Eq. (29) into Eq. (8):

$\left\{\begin{array}{l}\varepsilon_{r p}=\left[-\frac{\eta_{p} u_{e}^{R_{p}}}{R_{p}}+\frac{\eta_{p}\left(\varepsilon_{r}^{R_{p}}+\eta_{p} \varepsilon_{\theta}^{R_{p}}\right)}{\eta_{p}+1}\right]\left(\frac{R_{p}}{r}\right)^{\eta_{p}+1}+\frac{\varepsilon_{r}^{R_{p}}+\eta_{p} \varepsilon_{\theta}^{R_{p}}}{\eta_{p}+1} \\ \varepsilon_{\theta p}=\left[\frac{u_{e}^{R_{p}}}{R_{p}}-\frac{\varepsilon_{r}^{R_{p}}+\eta_{p} \varepsilon_{\theta}^{R_{p}}}{\eta_{p}+1}\right]\left(\frac{R_{p}}{r}\right)^{\eta_{p}+1}+\frac{\varepsilon_{r}^{R_{p}}+\eta_{p} \varepsilon_{\theta}^{R_{p}}}{\eta_{p}+1}\end{array}\right.$

\subsection{Stresses and displacement in the broken region $\left(R_{0} \leq r<R_{b}\right)$}

The stresses in the broken region can be solved by substituting Eq. (6) into Eq. (7) and considering the boundary condition $\sigma_{r}=p_{s}$ at $r=R_{0}$ :

$\left\{\begin{array}{l}\sigma_{r b}=\frac{N_{b}}{1-M_{b}}+\left(p_{s}-\frac{N_{b}}{1-M_{b}}\right)\left(\frac{R_{0}}{r}\right)^{1-M_{b}} \\ \sigma_{\theta b}=\frac{N_{b}}{1-M_{b}}+M_{b}\left(p_{s}-\frac{N_{b}}{1-M_{b}}\right)\left(\frac{R_{0}}{r}\right)^{1-M_{b}}\end{array}\right.$

In the broken region, the total strains of the surrounding rock are also composed of two parts as

$\left\{\begin{array}{l}\varepsilon_{r}=\varepsilon_{r b}+\varepsilon_{r}^{R_{b}} \\ \varepsilon_{\theta}=\varepsilon_{\theta b}+\varepsilon_{\theta}^{R_{b}}\end{array}\right.$

where $\varepsilon_{r}{ }^{R_{b}}$ and $\varepsilon_{\theta}{ }^{R_{b}}$ are the radial and tangential strains at $r=R_{b}$, respectively.

The displacement in the broken region can be derived by integrating Eqs. (8), (10), and (32) with the boundary condition of $u_{b}=u_{p}$ at $r=R_{b}$ :

$u_{b}=\left[u_{p}^{R_{b}}-\frac{\left(\varepsilon_{r}^{R_{b}}+\eta_{b} \varepsilon_{\theta}^{R_{b}}\right) R_{b}}{\eta_{b}+1}\right]\left(\frac{R_{b}}{r}\right)^{\eta_{b}}+\frac{\left(\varepsilon_{r}^{R_{b}}+\eta_{b} \varepsilon_{\theta}^{R_{b}}\right) r}{\eta_{b}+1}$

where $u_{p}{ }^{R_{b}}$ is the displacement at $r=R_{b}$.

\subsection{Post-peak region radii $\left(R_{p}\right.$ and $\left.\boldsymbol{R}_{b}\right)$}

To determine the stresses and deformations of the surrounding rock, the post-peak region radii $\left(R_{p}\right.$ and $\left.R_{b}\right)$ should be solved first.

When $r=R_{b}, c_{p}=c_{b}$, and $\varepsilon_{\theta p}=\varepsilon_{\theta} R_{b}$, the relationship between $R_{p}$ and $R_{b}$ can be determined by integrating Eq. (1) and Eq. (33): 


$$
\frac{R_{p}}{R_{b}}=\left[\frac{\left(\eta_{p}+1\right)\left(c_{b}-c_{0}\right) / S_{c}-\varepsilon_{r}^{R_{p}}+\varepsilon_{\theta}^{R_{p}}}{\left(\eta_{p}+1\right) u_{e}^{R_{p}} / R_{p}-\varepsilon_{r}^{R_{p}}-\eta_{p} \varepsilon_{\theta}^{R_{p}}}\right]^{\frac{1}{\eta_{p}+1}}
$$

With the boundary condition of $\sigma_{r p}=\sigma_{r b}$ at $r=R_{b}$, the following equation can be obtained by integrating Eq. (26) and Eq. (31):

$\frac{N_{b}}{1-M_{b}}+\left(\sigma_{r}^{R_{p}}-\frac{N_{b}}{1-M_{b}}\right)\left(\frac{R_{p}}{R_{b}}\right)^{1-M_{p}}=\frac{N_{b}}{1-M_{b}}+\left(p_{s}-\frac{N_{b}}{1-M_{b}}\right)\left(\frac{R_{0}}{R_{b}}\right)^{1-M_{b}}$

The post-peak region radii can be derived by substituting Eq. (34) into Eq. (35):

$$
\left\{\begin{array}{l}
R_{p}=R_{0} \cdot\left[\frac{\left(1-M_{b}\right) p_{s}-N_{b}}{\left(1-M_{b}\right) \sigma_{r}^{R_{p}}-N_{b}}\right]^{\frac{1}{1-M_{b}}} \\
R_{b}=R_{0} \cdot\left[\frac{\left(1-M_{b}\right) p_{s}-N_{b}}{\left(1-M_{b}\right) \sigma_{r}^{R_{p}}-N_{b}}\right]^{\frac{1}{1-M_{b}}} \cdot\left[\frac{\left(\eta_{p}+1\right) u_{e}^{R_{p}} / R_{p}-\varepsilon_{r}^{R_{p}}-\eta_{p} \varepsilon_{\theta}^{R_{p}}}{\left(\eta_{p}+1\right)\left(c_{b}-c_{0}\right) / M_{c}-\varepsilon_{r}^{R_{p}}+\varepsilon_{\theta}^{R_{p}}}\right]^{\frac{1}{\eta_{p}+1}}
\end{array}\right.
$$

Thus, the stresses distribution and surface displacement can be obtained by substituting Eq. (36) into Eqs. (22), (26), (31), and (33).

\section{EXAMPLE STUDY}

\subsection{Validation for the present solution}

The haulage tunnel in the Taoyuan coal mine in China is buried approximately $730 \mathrm{~m}$ underground with an approximate vertical stress of 19.4 MPa and an average horizontal stress of 21.7 MPa. The horizontal-to-vertical stress ratio is 1.12. The equivalent excavation radius of the tunnel is $3 \mathrm{~m}$, and the rock mass parameters are $E=1550 \mathrm{MPa}$, $\mu=0.28, c_{0}=4.3 \mathrm{MPa}, c_{b}=0.8 \mathrm{MPa}, S_{c}=-420 \mathrm{MPa}, \varphi_{0}=34^{\circ}, \varphi_{b}=19^{\circ}, S_{\varphi}=-1800^{\circ}$, and $\psi_{i}=10^{\circ}$.

The finite element program COMSOL, based on Mohr-Coulomb criterion and the strain-softening model, was introduced to study the stresses distribution of the surrounding rock. To satisfy the same conditions as the numerical simulation, the analytical results based on the Mohr-Coulomb criterion in the present study were also calculated. The stresses distribution obtained by numerical simulation and the comparison between the analytical and numerical results are shown in Figure 4 and Figure 5, respectively. The stresses distribution around the circular tunnel is consistent with the numerical simulation results, which validates the correctness of the present solution.

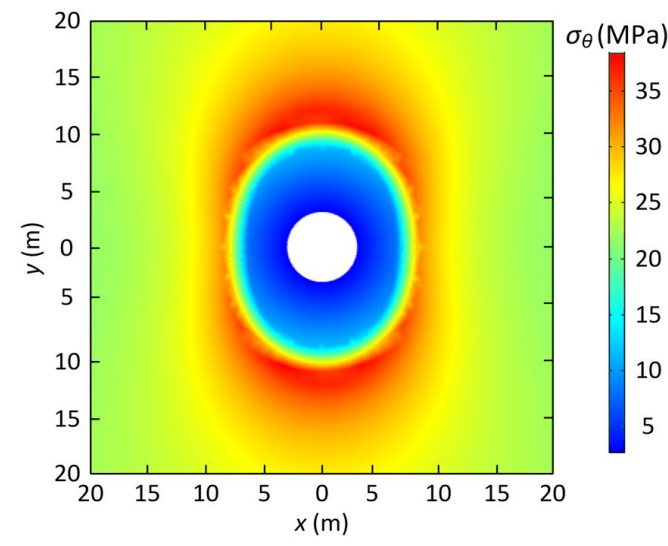

(a) $\sigma_{\theta}$

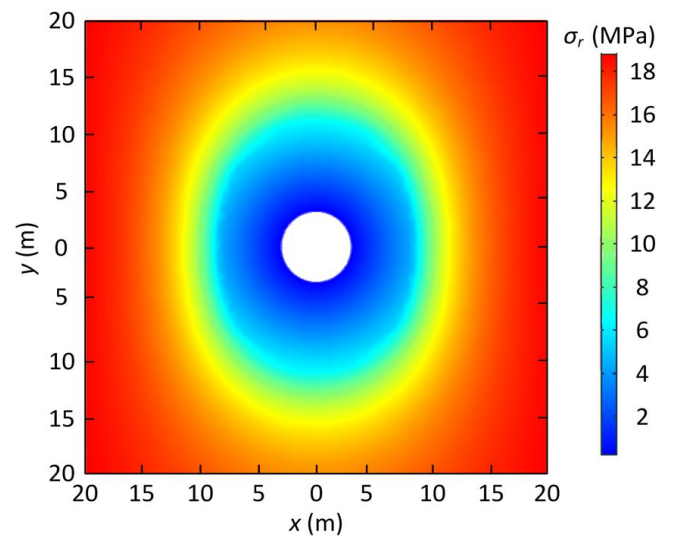

(b) $\sigma_{r}$

Figure 4: Stresses distribution obtained by numerical simulation. 


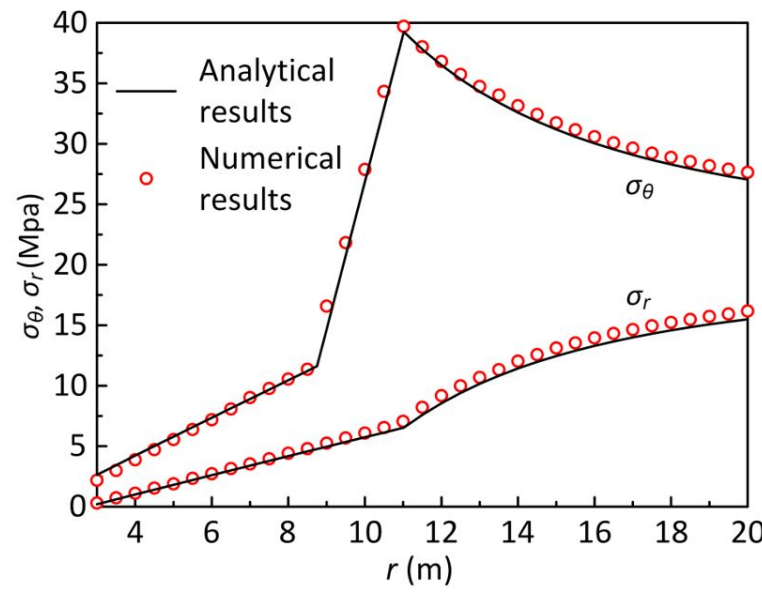

(a) tunnel crown

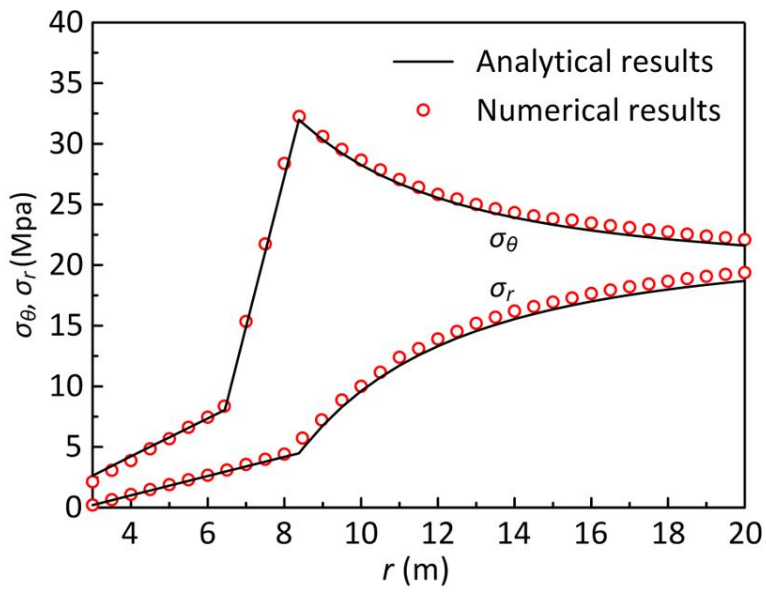

(b) tunnel side

Figure 5: Comparison of the stresses distribution between the analytical and numerical results.

\subsection{Stress and deformation of the surrounding rock of a tunnel under a non-uniform stress field}

Figure 6 shows the post-peak region radii and surface displacement of the surrounding rock. The post-peak region radii and the surface displacement $\left(u_{0}\right)$ vary with direction because of the non-uniform stress field. For instance, the $R_{p}$, $R_{b}$, and $u_{0}$ values at $\vartheta=0$ are $5.00 \mathrm{~m}, 3.95 \mathrm{~m}$, and $0.14 \mathrm{~m}$, respectively; however, the $R_{p}, R_{b}$, and $u_{0}$ values at $\vartheta=\pi / 2$ are $6.43 \mathrm{~m}, 5.24 \mathrm{~m}$, and $0.28 \mathrm{~m}$, with an increment of $28.60 \%, 32.66 \%$, and $100.00 \%$, respectively. Additionally, the stresses distribution at different locations of the tunnel in a non-uniform stress field is also different (Figure 7). The peak tangential stress at the tunnel crown is $41.79 \mathrm{MPa}$, which is approximately 1.29 times that at the tunnel side. Therefore, the tunnel crown experiences a more severe rupture than tunnel sides.

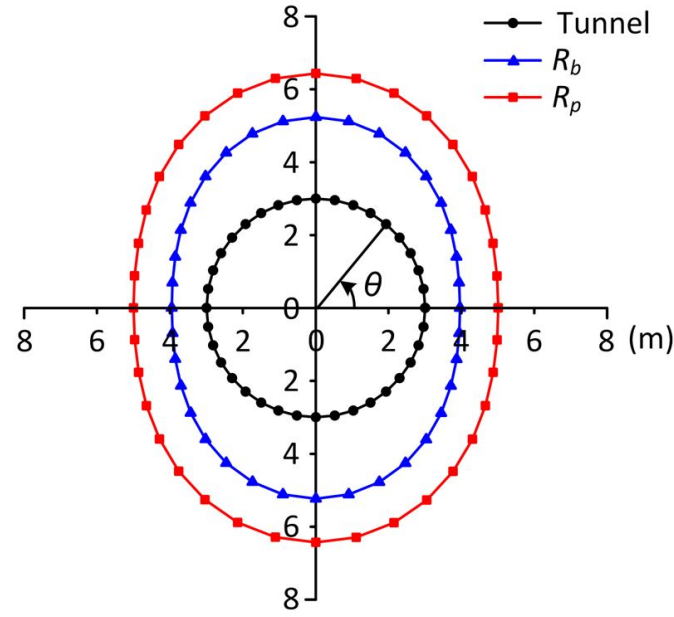

(a) $R_{p}$ and $R_{b}$

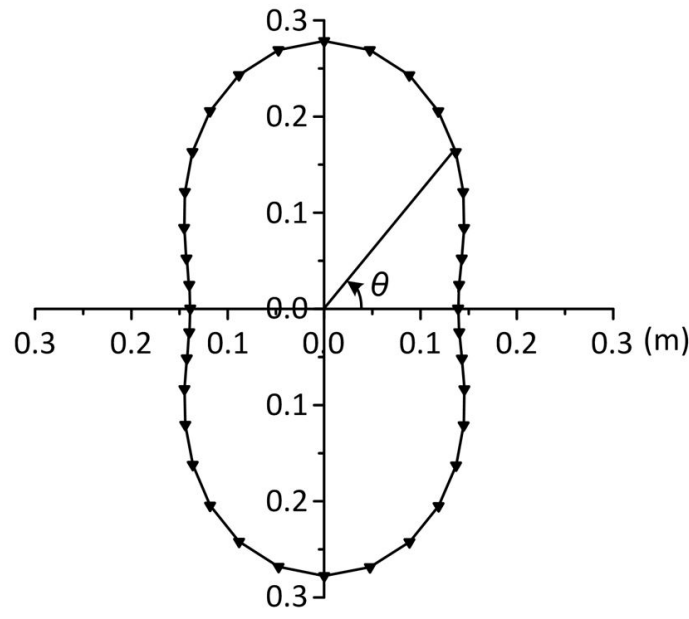

(b) $u_{0}$

Figure 6: Post-peak region radii and surface displacement around the tunnel in a non-uniform stress field. 


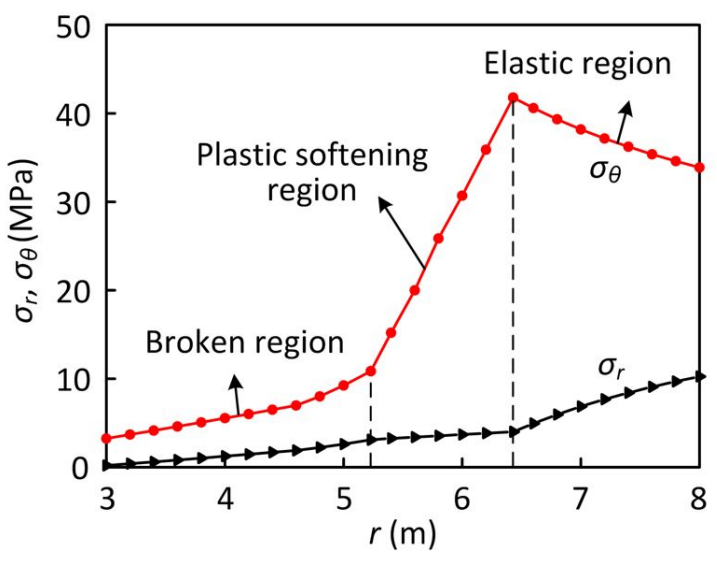

(a) tunnel crown

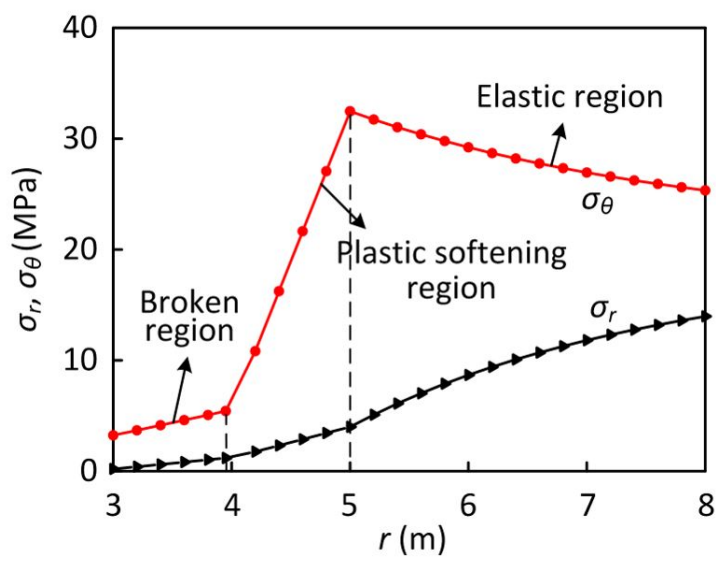

(b) tunnel side

Figure 7: Stresses distribution at tunnel crown and tunnel side in a non-uniform stress field.

\subsection{Geomechanical parameters analysis}

\subsubsection{Horizontal-to-vertical stress ratio}

To analyze the sensitivity of the horizontal-to-vertical stress ratio $(\lambda)$ to the deformations of the surrounding rock, the $\lambda$ value is selected as $0.9,1.0,1.1$, and 1.2 while keeping all the other parameters constant at their basic values in this case. The post-peak region radii and surface displacement around the tunnel with different stress ratios are shown in Figure 8. The shapes of the post-peak regions are determined by the stress ratio. Only when $\lambda=1$ are the post-peak regions circular and the surface displacements in different directions in the tunnel equal. In addition, when $\lambda<1$, the post-peak region radii and surface displacement show a nonlinear decrease as $\vartheta$ changes from 0 to $\pi / 2$. The deformation at the tunnel side is most severe. On the contrary, when $\lambda>1$, the post-peak region radii and surface displacement show an increase as $\vartheta$ changes from 0 to $\pi / 2$. The tunnel crown suffers from the most severe damage and needs more support. Therefore, the horizontal-to-vertical stress ratio exerts a significant effect on the tunnel deformations and the support design of a tunnel should consider the horizontal-to-vertical stress ratio. 


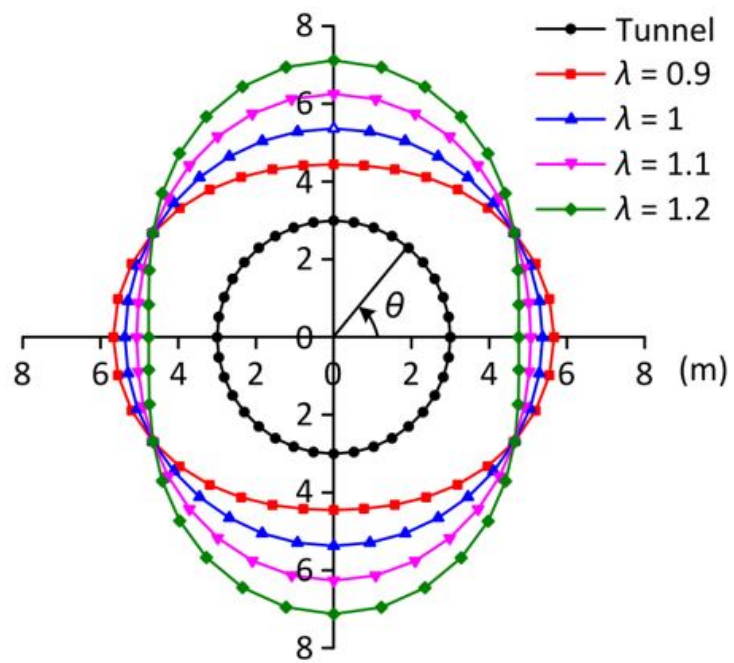

(a) $R_{p}$

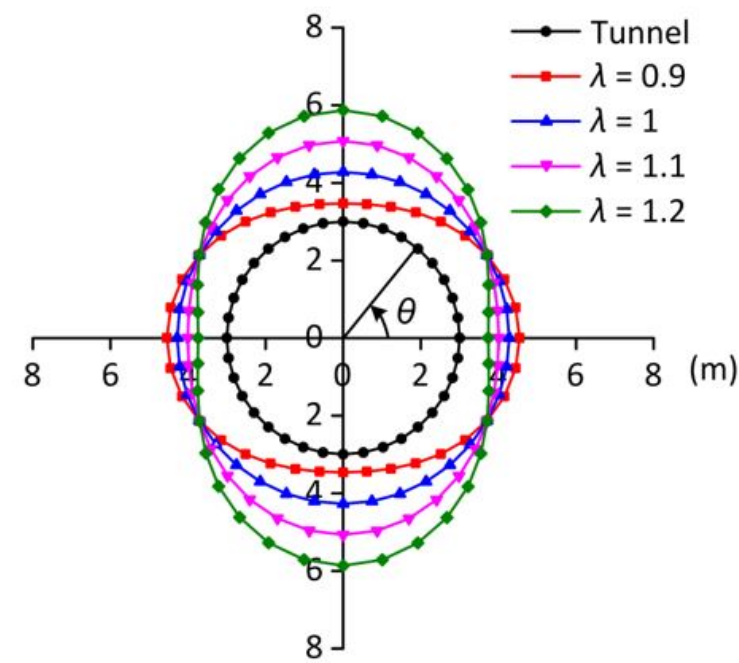

(b) $R_{b}$

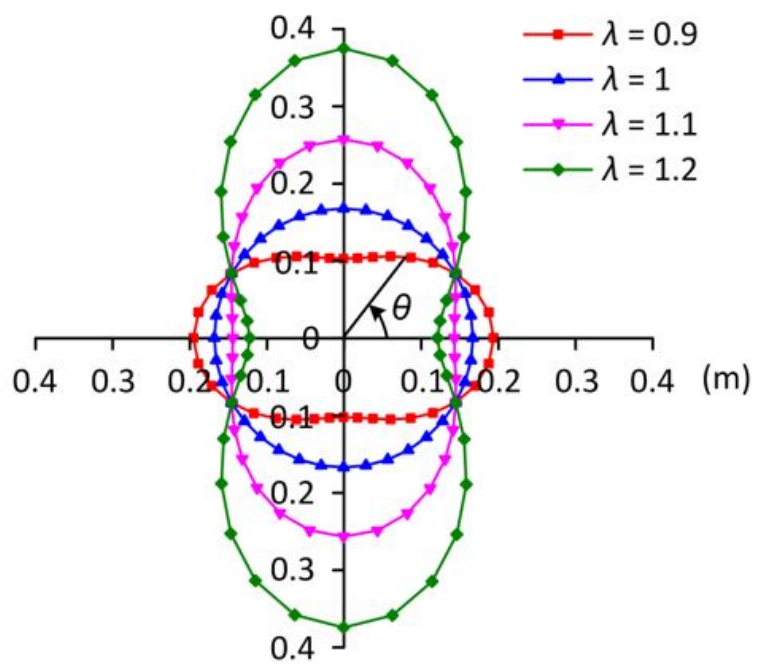

(c) $u_{0}$

Figure 8: Post-peak region radii and surface displacement around the tunnel under different horizontal-to-vertical stress ratio.

\subsubsection{Intermediate principal stress}

To discuss the influence of intermediate principal stress on the post-peak region radii and surface displacement, the analytical solution in this study is compared with the results obtained using the Mohr-Coulomb criterion (Figure 9). The $R_{p}, R_{b}$, and $u_{0}$ values computed by the Mohr-Coulomb criterion are all larger than those computed by the MogiCoulomb criterion. For example, the $R_{p}, R_{b}$, and $u_{0}$ values at $\vartheta=\pi / 2$ from the Mogi-Coulomb criterion are $6.43 \mathrm{~m}$, $5.24 \mathrm{~m}$, and $0.28 \mathrm{~m}$, respectively; whereas, the results from the Mohr-Coulomb criterion are $11.02 \mathrm{~m}, 8.75 \mathrm{~m}$, and $0.81 \mathrm{~m}$, with an increment of $71.38 \%, 66.98 \%$, and $189.29 \%$, respectively. The primary reason for these diffirent results is that the intermediate principal stress is completely ignored by the Mohr-Coulomb criterion, which causes an increased unnecessary support design. Therefore, it is more reasonable to take the intermediate principal stress into consideration in engineering applications. 


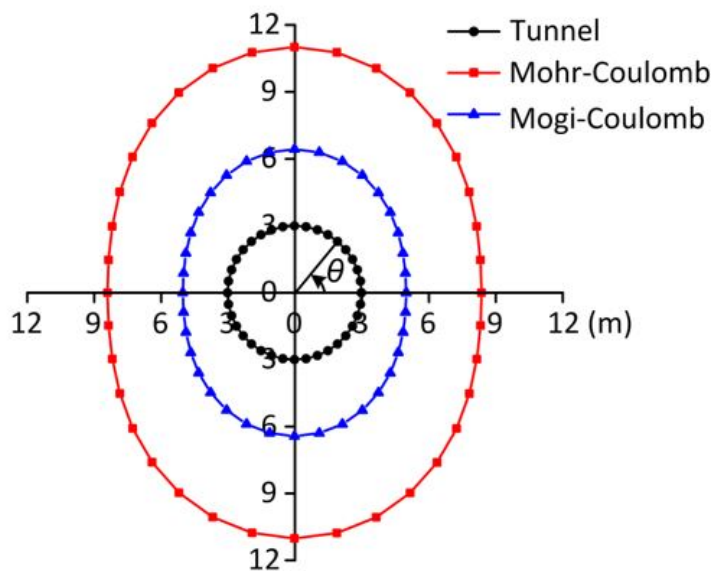

(a) $R_{p}$

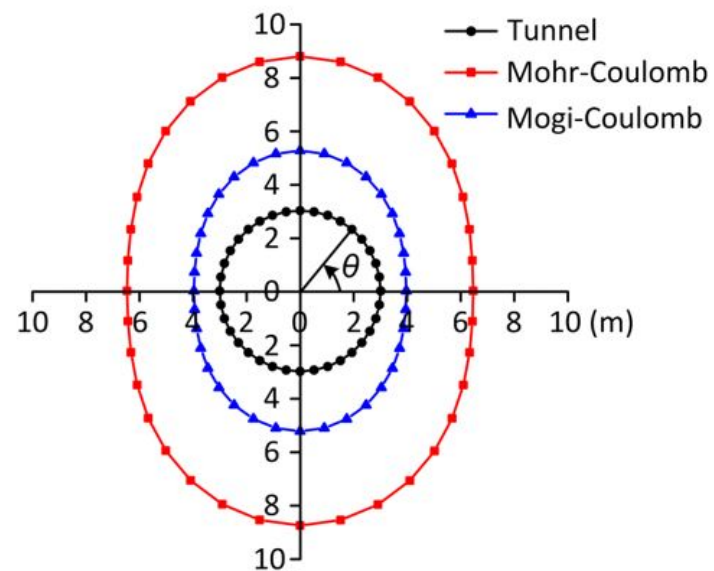

(b) $R_{b}$

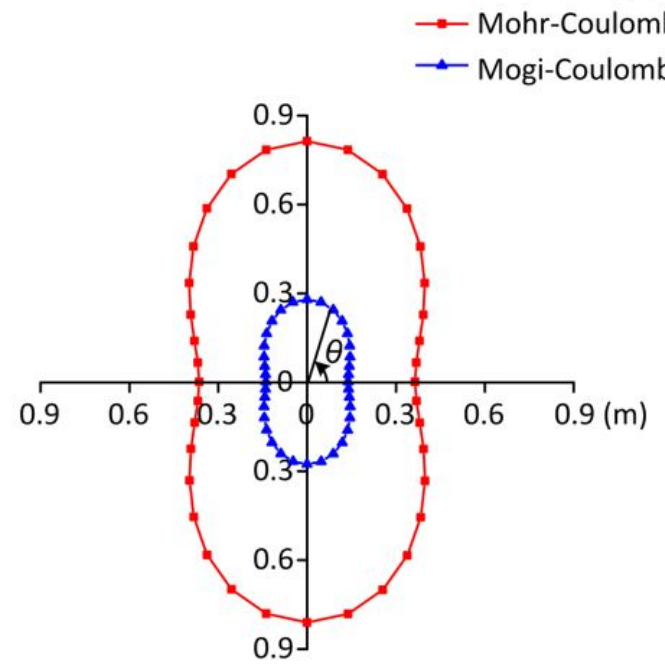

(c) $u_{0}$

Figure 9: Post-peak region radii and surface displacement around the tunnel based on different strength criteria.

\subsubsection{Residual cohesion and residual internal friction angle}

Figures 10 and 11 show the sensitivity of the residual cohesion and residual internal friction angle to the post-peak region radii and surface displacement. The $R_{p}, R_{b}$, and $u_{0}$ values all decrease with increasing $c_{b}$ and $\varphi_{b}$. For example, as $c_{b}$ increases from $0.8 \mathrm{MPa}$ to $2.6 \mathrm{MPa}, R_{p}, R_{b}$, and $u_{0}$ decrease by $1.44 \mathrm{~m}, 0.70 \mathrm{~m}$, and $0.08 \mathrm{~m}$, with a reduction of $22.42 \%, 13.39 \%$, and $28.42 \%$, respectively. As $\varphi_{b}$ increases from $19^{\circ}$ to $28^{\circ}, R_{p}, R_{b}$, and $u_{0}$ decrease by $1.51 \mathrm{~m}, 0.76 \mathrm{~m}$, and $0.12 \mathrm{~m}$, with a reduction of $23.46 \%, 14.48 \%$, and $42.09 \%$, respectively. Therefore, both the residual cohesion and residual internal friction angle exert a crucial influence on the post-peak region radii and surface displacement. The rock mass bearing capacity gradually increases with the increasing $c_{b}$ and $\varphi_{b}$. As a result, some measures, such as grouting, can be used to increase the residual cohesion and residual internal friction angle of the rock mass and ensure tunnel stability. 


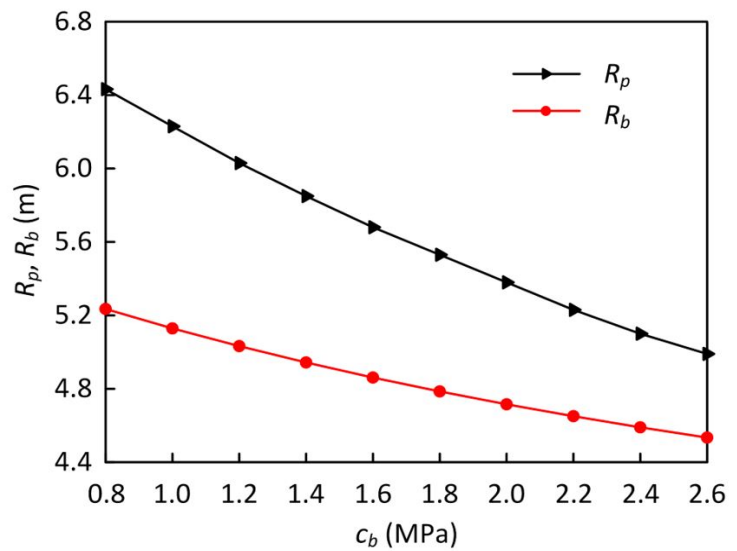

(a) $R_{p}$ and $R_{b}$

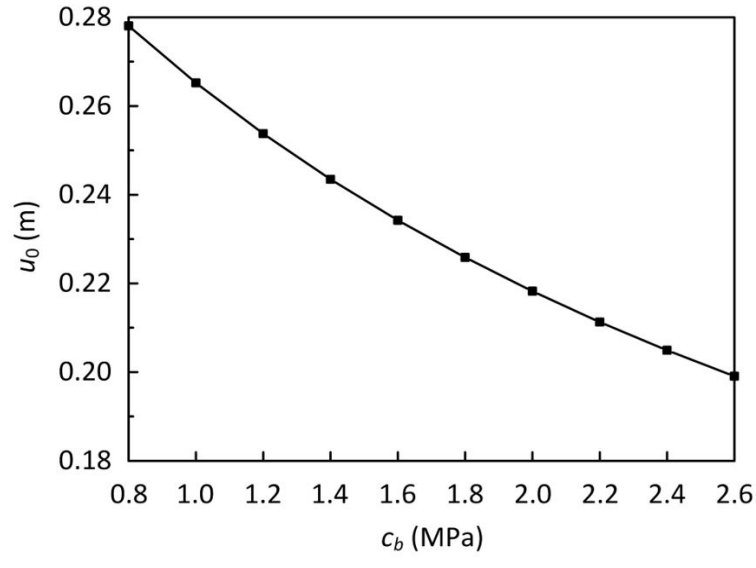

(b) $u_{0}$

Figure 10: Influence of residual cohesion on the post-peak region radii and surface displacement.

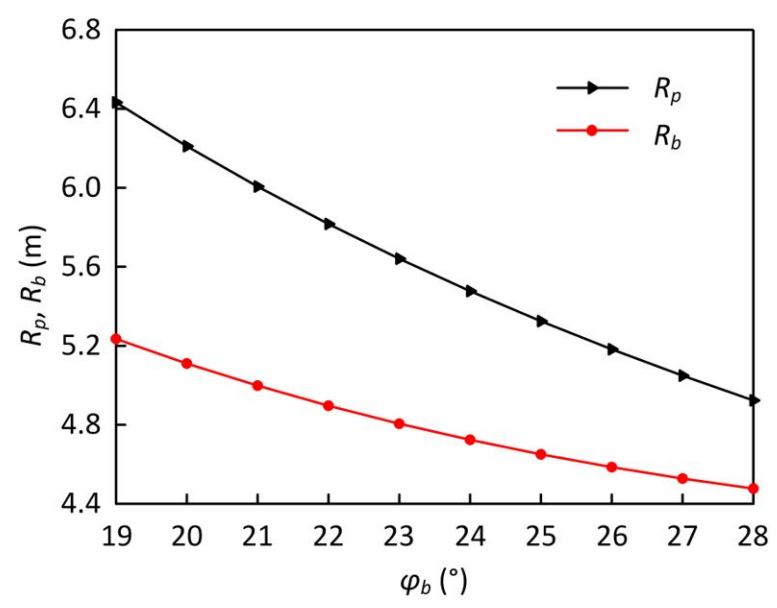

(a) $R_{p}$ and $R_{b}$

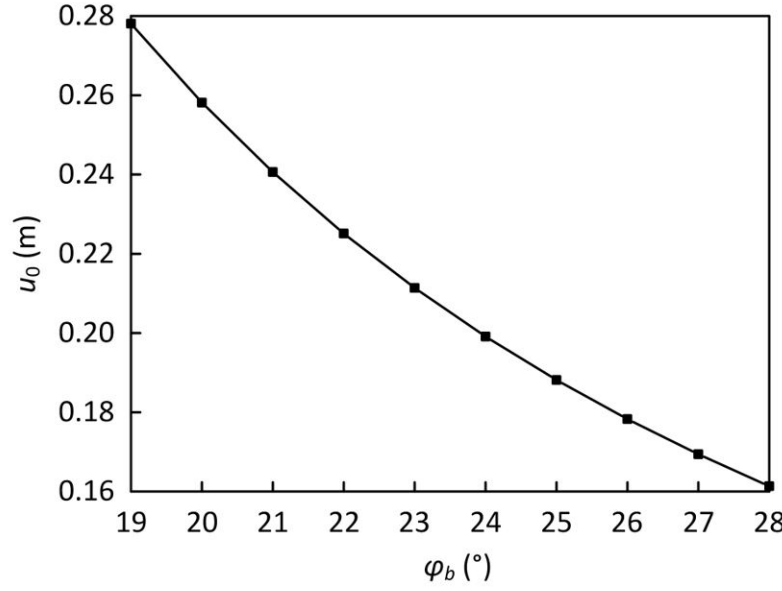

(b) $u_{0}$

Figure 11: Influence of residual internal friction angle on the post-peak region radii and surface displacement.

\section{CONCLUSIONS}

Based on the strain-softening model and Mogi-Coulomb criterion, a new unified solution for the stresses distribution and displacement of the surrounding rock of a tunnel in a non-uniform stress field was deduced. The conclusions can be summarized as follows:

1. (1) Due to the non-uniform stress field, the post-peak region radii and stresses distribution around the tunnel vary with direction. When $\lambda<1$, the post-peak region radii and surface displacement show a nonlinear decrease as $\vartheta$ changes from 0 to $\pi / 2$. The deformation at the tunnel side is most severe. On the contrary, when $\lambda>1$, the postpeak region radii and surface displacement show an increase as $\vartheta$ changes from 0 to $\pi / 2$. The tunnel crown suffers from the most damage and needs more support. Therefore, the support parameter design should account for the influence of the horizontal-to-vertical stress ratio.

2. (2) The post-peak region radii and surface displacement under the Mohr-Coulomb criterion are larger than those under the Mogi-Coulomb criterion, which is the result of neglecting the intermediate principal stress in the MohrCoulomb criterion. Therefore, consideration of the intermediate principal stress with an appropriate strength criterion can lead to a more reasonable tunnel support design.

3. (3) Tunnels surrounded by rock masses with a higher residual cohesion and residual internal friction angle have lower post-peak region radii and surface displacement. Therefore, deformation of the tunnel surrounding rock can be effectively controlled by increasing the residual cohesion and residual internal friction angle. 


\section{Acknowledgments}

This study was supported by National Key Research and Development Program of China (No. 2017YFC0603004) and the support is gratefully acknowledged.

Author's Contribuitions: Conceptualization, H Fan and L Wang; Methodology, H Fan and W Liu; Formal analysis, H Fan; Validation, L Wang; Writing - original draft, H Fan and W Liu; Writing - review \& editing, L Wang; Funding acquisition, L Wang.

\section{Editor: Marcílio Alves}

\section{References}

Al-Ajmi, A.M., Zimmerman, R.W. (2005). Relation between the Mogi and the Coulomb failure criteria. International Journal of Rock Mechanics and Mining Science 42: 431-439.

Alejano, L.R., Alonso, E., Rodríguez-Dono, A., Fernández-Manín, G. (2010). Application of the convergence-confinement method to tunnels in rock masses exhibiting Hoek-Brown strain-softening behaviour. International Journal of Rock Mechanics and Mining Science 47: 150-160.

Alejano, L.R., Rodriguez-Dono, A., Alonso, E., Fdez.-Manín, G. (2009). Ground reaction curves for tunnels excavated in different quality rock masses showing several types of post-failure behaviour. Tunnelling and Underground Space Technology 24: 689705.

Benz, T., Schwab, R. (2008). A quantitative comparison of six rock failure criteria. International Journal of Rock Mechanics and Mining Science 45: 1176-1186.

Brown, E.T., Bray, J.W., Ladanyi, B., Hoek, E. (1983). Ground response curves for rock tunnels. Journal of Geotechnical Engineering 109: 15-39.

Chang, C., Haimson, B. (2012). A failure criterion for rocks based on true triaxial testing. Rock Mechanics and Rock Engineering 45: 1007-1010.

Chen, R., Tonon, F. (2011). Closed-form solutions for a circular tunnel in elastic-brittle-plastic ground with the original and generalized Hoek-Brown failure criteria. Rock Mechanics and Rock Engineering 44: 169-178.

Cui, L., Zheng, J., Zhang, R., Dong, Y. (2015). Elasto-plastic analysis of a circular opening in rock mass with confining stressdependent strain-softening behaviour. Tunnelling and Underground Space Technology 50: 94-108.

Detournay, E., Fairhurst, C. (1987). Two-dimensional elastoplastic analysis of a long, cylindrical cavity under non-hydrostatic loading. International Journal of Rock Mechanics and Mining Science and Geomechanics Abstracts 24:197-211.

Detournay, E., St. John, C. (1988). Design charts for a deep circular tunnel under non-uniform loading. Rock Mechanics and Rock Engineering 21: 119-137.

Galin, L.A. (1946). Plane elastic-plastic problem: plastic regions around circular holes in plates and beams. Prikladnaia Matematika i Mechanika 10: 365-386.

Han, J., Li, S., Li, S., Yang, W. (2013). A procedure of strain-softening model for elasto-plastic analysis of a circular opening considering elasto-plastic coupling. Tunnelling and Underground Space Technology 37: 128-134.

Jiang, B., Gu, S., Wang, L., Zhang, G., Li, W. (2019). Strainburst process of marble in tunnel-excavation-induced stress path considering intermediate principal stress. Journal of Central South University 26: 984-999.

Li, Y., Cao, S., Fantuzzi, N., Liu, Y. (2015). Elasto-plastic analysis of a circular borehole in elastic-strain softening coal seams. International Journal of Rock Mechanics and Mining Science 80: 316-324.

Li, Z., Wang, L., Lu, Y., Li, W., Wang, K., Fan, H. (2019). Experimental investigation on True Triaxial Deformation and Progressive Damage Behaviour of Sandstone. Scientific Reports 9: 3386.

Lu, Y., Wang, L., Yang, F., Li, Y., Chen, H. (2010). Post-peak strain softening mechanical properties of weak rock. Chinese Journal of Rock Mechanics and Engineering 29: 640-648. (In Chinese) 
Mogi, K. (1971). Fracture and flow of rocks under high triaxial compression. Journal of Geophysical Research 76: 1255-1269.

Mogi, K. (1981). Flow and fracture of rocks under general triaxial compression. Applied Mathematics and Mechanics 2: 635651.

Mohammad, R.Z., Ahmad, F. (2015). Elastic-brittle-plastic analysis of circular deep underwater cavities in a Mohr-Coulomb rock mass considering seepage forces. International Journal of Geomechanics 15: 1-10.

Mohammad, R.Z., Ahmad, F. (2016). Analytical solutions for the stresses and deformations of deep tunnels in an elastic-brittleplastic rock mass considering the damaged zone. Tunnelling and Underground Space Technology 58: 186-196.

Park, K. (2015). Large strain similarity solution for a spherical or circular opening excavated in elastic-perfectly plastic media. International Journal for Numerical and Analytical Methods in Geomechanics 39: 724-737.

Park K., Kim, Y. (2006). Analytical solution for a circular opening in an elastic-brittle-plastic rock. International Journal of Rock Mechanics and Mining Science 43: 616-622.

Sharan, S.K. (2003). Elastic-brittle-plastic analysis of circular openings in Hoek-Brown media. International Journal of Rock Mechanics and Mining Science 40: 817-824.

Sharan, S.K. (2008). Analytical solutions for stresses and displacements around a circular opening in a generalized Hoek-Brown rock. International Journal of Rock Mechanics and Mining Science 45: 78-85.

Shen, B. (2013). Coal mine roadway stability in soft rock: a case study. Rock Mechanics and Rock Engineering 47: $2225-2238$.

Simanjuntak, T.D.Y.F., Marence, M., Mynett, A.E., Schleiss, A.J. (2014). Pressure tunnels in non-uniform in situ stress conditions. Tunnelling and Underground Space Technology 42: 227-236.

Singh, A., Rao, K.S., Ayothiraman, R. (2017). Effect of intermediate principal stress on cylindrical tunnel in an elasto-plastic rock mass. Procedia Engineering 173: 1056-1063.

Singh, A., Kumar, C., Kannan, L.G., Rao, K.S., Ayothiraman, R. (2018). Engineering properties of rock salt and simplified closedform deformation solution for circular opening in rock salt under the true triaxial stress state. Engineering Geology 243:218230.

Wang, C., Wang, Y., Lu, S. (2000). Deformational behaviour of roadways in soft rocks in underground coal mines and principles for stability control. International Journal of Rock Mechanics and Mining Science 37: 937-946.

Wang, S., Wang, W., Wu, Z. (2010a). Study of relationship between evolution of post-peak strength parameters and stressstrain curves of geomeaterials. Chinese Journal of Rock Mechanics and Engineering 29: 1524-1529. (In Chinese)

Wang, S., Yin, X., Tang, H., Ge, X. (2010b). A new approach for analyzing circular tunnel in strain-softening rock masses. International Journal of Rock Mechanics and Mining Science, 47, 170-178.

Wang, X.F., Jiang, B.S., Zhang, Q., Lu, M.M., Chen, M. (2019). Analytical solution of circular tunnel in elastic-viscoplastic rock mass. Latin American Journal of Solids and Structures 16: 1-19.

Zhang, L., Cao, P., Radha, K.C. (2010). Evaluation of rock strength criteria for wellbore stability analysis. International Journal of Rock Mechanics and Mining Science 47: 1304-1316.

Zhang, Q., Jiang, B., Wang, S., Ge, X., Zhang, H. (2012). Elasto-plastic analysis of a circular opening in strain-softening rock mass. International Journal of Rock Mechanics and Mining Science 50: 38-46.

Zhao, Z.; Wang, W.; Wang, L. (2013). Response models of weakly consolidated soft rock roadway under different interior pressures considering dilatancy effect. Journal of Central South University 20: 3736-3744. 